\title{
Controversies in Gynaecologic Oncology
}

\author{
Amita Maheshwari ${ }^{1} \cdot$ Sudeep Gupta $^{1}$ (i)
}

Received: 3 October 2017/ Accepted: 5 October 2017/Published online: 18 December 2017

(C) Association of Gynecologic Oncologists of India 2017

Controversies are the life blood of progress in any field of human endeavour-gynaecologic oncology is no exception. Because different individuals or groups of individuals hold divergent opinions on a subject, they, or others, are forced to assimilate the divergences and contemplate future action. Unlike physical sciences, biology_and medicinecontinue to be largely empirical, based on observations and also verifiable by them. 'Observing' has evolved from Leeuwenhoek's microscope [1] and James Lind's exploits on board Salisbury [2] to an enormous (and expensive) enterprise involving large, sophisticated clinical trials and vast amounts of data generated by 'omics' and other experiments.

Why then do we continue to be uncertain about the benefits (or otherwise) of diagnostic procedures and treatments? The answer lies in the profoundly probabilistic nature of clinical reasoning, itself a result of sampling human variation [3]. Although most humans, including physicians, remain uncomfortable with uncertainty, it is also apparent that there are no blacks (or whites) but only shades of grey.

It is in the spirit of 'shades of grey' that we present to you this special issue of Indian Journal of Gynaecologic Oncology on the occasion of the joint Annual Conference of Association of Gynaecologic Oncologists of India and Women's Cancer Initiative-Tata Memorial Hospital. A pair of colleagues presents opposing points of view on each of four chosen themes that continue to generate debate among physicians caring for women with gynaecologic cancers. We chose these themes because they present

Sudeep Gupta

sudeepgupta04@yahoo.com

Tata Memorial Centre, Mumbai, India matters of practical everyday decision making and present no clear answers even to astute clinicians who have thoroughly appraised relevant data. Drs. Rajappa and Agarwal debate anti-angiogenic therapy in epithelial ovarian cancer, Drs. Shigeki and Kulkarni HIPEC in same disease, Drs. Guntupalli and Nag germline testing for hereditary predisposition in epithelial ovarian cancer patients and, finally, Drs. Biswas and Goyal pelvic and retroperitoneal lymphadenectomy in endometrial cancer. You may have noted that three of these debates place a more expensive and potentially more harmful—but also potentially more efficacious - treatment against another standard. The choice is therefore a balance between harms and expense on one side and benefit on the other-provided one is convinced that some benefit exists. An added complexity is that 'benefit' may exist for some, but not all, patients with a given condition and existing data are unable to untangle such a subgroup decisively.

It is known that protagonists assume extreme positions in the 'debating' mode, but in so doing they also dissect evidence with strictest of scrutiny and uncover facets that their more 'reasonable' selves may have overlooked. The 'debates' are therefore likely to be a sharper, if somewhat polarized, take on these topics and illuminate the readers in unanticipated ways. Although we, the guest editors, are ourselves partial to one side of each debate, we will refrain from placing those views here and will leave you, the readers, to enjoy the debates unadulterated and contemplate the possibilities.

Finally, before we sign off, debates are not wars. In this context, we also recommend to you this excellent Op-ed in New York Times, 'The Dying Art of Disagreement' [4]. We hope that we will be artful about our disagreements, will do so civilly, continue to respect those holding the opposing viewpoint and acknowledge their right to hold them. 


\section{Compliance with Ethical Standards}

\section{Conflict of interest None.}

\section{References}

1. Hoole S. The select works of Antony van Leeuwenhoek. London: The Philanthropic Society; 1807. https://archive.org/details/ selectworksofant02leeu.
2. Lind J. A treatise of the scurvy. In three parts. Containing an inquiry into the nature, causes and cure, of that disease. Together with a critical and chronological view of what has been published on the subject. Edinburgh: Printed by Sands, Murray and Cochran for A Kincaid and A Donaldson; (1753).

3. Gupta S. Biological reasoning.... and statistics.... Indian J Med Paediatr Oncol. 2009;30:91.

4. Stephens B. The dying art of disagreement. The New York Times September 24, 2017. https://www.nytimes.com/2017/09/24/opi nion/dying-art-of-disagreement.html?_r=0. Accessed 29 Sept 2017. 